\title{
Using hydrothermal time concepts to model seed germination response to temperature dormancy loss and priming effects in Elymus elymoides
}

\author{
Phil S. Allen \\ Phil_Allen@byu.edu \\ Susan E. Meyer \\ Susan B. Debaene-Gill
}

Follow this and additional works at: https://scholarsarchive.byu.edu/facpub

Part of the Animal Sciences Commons, and the Plant Sciences Commons

\section{Original Publication Citation}

Seed Science Research 1.3(Sep 2): 213-223.

\section{BYU ScholarsArchive Citation}

Allen, Phil S.; Meyer, Susan E.; and Debaene-Gill, Susan B., "Using hydrothermal time concepts to model seed germination response to temperature dormancy loss and priming effects in Elymus elymoides" (2000). Faculty Publications. 588.

https://scholarsarchive.byu.edu/facpub/588

This Peer-Reviewed Article is brought to you for free and open access by BYU ScholarsArchive. It has been accepted for inclusion in Faculty Publications by an authorized administrator of BYU ScholarsArchive. For more information, please contact ellen_amatangelo@byu.edu. 


\title{
Using hydrothermal time concepts to model seed germination response to temperature, dormancy loss, and priming effects in Elymus elymoides
}

\author{
Susan E. Meyer ${ }^{1 \star}$, Susan B. Debaene-Gill², and Phil S. Allen² \\ ${ }^{1}$ USDA Forest Service, Rocky Mountain Research Station, Shrub Sciences Laboratory, 735 N. 500 East, Provo, \\ UT 84606, USA; '2Department of Agronomy and Horticulture, Brigham Young University, Provo, UT 84602, USA
}

\begin{abstract}
Hydrothermal time (HTT) describes progress toward seed germination under various combinations of incubation water potential $(\mathrm{I})$ and temperature $(T)$. To examine changes in HTT parameters during dormancy loss, seeds from two populations of the bunchgrass Elymus elymoides were incubated under seven temperature regimes following dry storage at 10, 20 and $30^{\circ} \mathrm{C}$ for intervals from 0 to 16 weeks. Fully after-ripened seeds were primed for 1 week at a range of $\mathrm{s}$. Data on germination rate during priming were used to obtain a HTT equation for each seed population, while data obtained following transfer to water were used to calculate HTT accumulation during priming. HTT equations accurately predicted germination time course curves if mean base water potential, b(50), was allowed to vary with temperature. ${ }_{b}(50)$ values increased linearly with temperature, explaining why germination rate does not increase with temperature in this species.

${ }_{b}(50)$ showed a linear decrease as a function of thermal time in storage. Slopes for the $T \times{ }_{b}(50)$ relationship did not change during after-ripening. This thermal afterripening time model was characterized by a single base temperature and a constant slope across temperatures for each collection. Because the difference between initial and final ${ }_{b}(50) s$ was uniform across temperatures, the thermal after-ripening requirement was also a constant. When seeds were primed for 1 week at -4 to $-20 \mathrm{MPa}$, accumulation of HTT was a uniform $20 \%$ of the total HTT requirement. When primed at 0 to $-4 \mathrm{MPa}$, HTT accumulation decreased linearly with decreasing priming potential, and a hydrothermal priming time model using a constant minimum priming potential adequately described priming effects. Use of these simple HTT relationships will facilitate modelling of germination phenology in the field.
\end{abstract}

*Correspondence

Fax: + 1 (801) 3756968

Email: semeyer@sisna.com
Keywords: after-ripening, dormancy, Elymus elymoides, hydrothermal time, modelling, priming, seed germination

\section{Introduction}

Seed germination is strongly influenced by temperature $(T)$ and water potential ( ). Accumulation of progress toward radicle emergence under various combinations of $T$ and can be described using hydrothermal time (Gummerson, 1986; Dahal and Bradford, 1994; Bradford, 1995):

$$
\mathrm{HT}=(\quad \mathrm{b}(g))\left(\begin{array}{ll}
T & \left.T_{\mathrm{b}}\right) t_{g},
\end{array}\right.
$$

where ${ }_{\mathrm{HT}}$ is the hydrothermal time required for germination (e.g. MPa-degree-days), and $T$ are the water potential and temperature of the incubation medium, $T_{\mathrm{b}}$ is the base temperature at or below which germination will not occur, $b(g)$ is the base water potential at or below which germination of the $g$ fraction will not occur, and $t_{g}$ is the actual time required for germination of the $g$ fraction. Hydrothermal time is essentially an extension of the more familiar thermal time (e.g. degree-days) used to describe rates of numerous biological processes including seed germination. Inclusion of terms for water potential allows the germination delay due to incubation at increasingly negative water potentials to be quantified. ${ }_{H T}$ and $T_{b}$ in equation (1) are assumed to be constant for a seed population, while

$b(g)$ and $t_{g}$ vary with germination fraction. Distribution of ${ }_{b}(g)$ is assumed to be approximately normal, with a mean ${ }_{b}(50)$ and standard deviation

This normal distribution of ${ }_{b}(g)$ s generates the characteristic cumulative inverse normal distribution of $t_{g} \mathrm{~s}$ seen in germination time courses.

A significant advantage of using hydrothermal time models to describe seed germination is that, once ${ }_{\mathrm{HT}^{\prime}} \mathrm{b}_{\mathrm{b}}(50), \mathrm{T}_{\mathrm{b}^{\prime}}$ and (standard deviation of $\left.{ }_{b}\right)$ are known, germination time courses can be 
predicted for any $T$ and combination. Probit analysis techniques are typically used to estimate the values of ${ }_{\mathrm{HT}^{\prime}} \mathrm{b}(50)$, and from time course data at two or more and $T$ values (Bradford, 1990; Dahal and Bradford, 1994; Christensen et al., 1996). Because base water potential is inversely proportional to germination rate at a given, treatments or conditions that increase $b(g)$ will decrease the germination rate, while those that decrease ${ }_{b}(g)$ will increase the germination rate. Further, where a shift in $b(50)$ changes the fraction of the seed population that is at or below ${ }_{b}(g)$ at a particular, germination percentage will also be affected (i.e. because a seed will not germinate below its base water potential just as it is unable to germinate below the base temperature). As the distribution of base water potentials within a population shifts downward, germination will occur more rapidly and to a higher percentage at a given incubation water potential. This is because the rate at which a seed accumulates hydrothermal time (progress toward germination) is determined by the temperature and water potential of incubation in relation to the base temperature and base water potential for that seed. The larger the differences $\left(T-T_{\mathrm{b}}\right)$ and $\left(-{ }_{\mathrm{b}}(g)\right)$, the faster the seed will accrue hydrothermal time and the sooner it will germinate.

Examples of altered germination due to a shift in distribution of base water potentials include increased germination rates as muskmelon seeds matured (Welbaum et al., 1990), increased germination capacity under osmotic stress due to a single-gene mutation in Arabidopsis thaliana (Saleki et al., 1993), and changes in germination rate and percentage associated with manipulation of gibberellic acid and abscisic acid levels in seeds (Ni and Bradford, 1992, 1993a, b). In general, $T_{b}$ varies little among seeds within a population, although exceptions have been reported (reviewed by Bradford, 1995). To date, most studies involving hydrothermal time have emphasized the importance of ${ }_{b}(50)$ and

The discovery that base water potentials within a population of seeds decrease during dry afterripening led to use of ${ }_{b}(50)$ as an index of dormancy status in the annual grass Bromus tectorum L. (Christensen et al., 1996; Allen and Meyer, 1998; Bauer et al., 1998). Allowing this single HTT parameter to vary in models of after-ripening while holding all others constant accounted for variation in germination time courses as after-ripening progressed, variation in the time required for seed populations to completely after-ripen, and the upward shift in optimum incubation temperature as seeds lost dormancy (Christensen et al., 1996). Furthermore, decreases in germination rate and percentage that were observed above the optimum incubation temperature were also explained by an increase $b(50)$ as incubation temperature increased.

Extension of this model led to the concept of thermal after-ripening time to explain dormancy loss in B. tectorum, based on the observation that the rate of change in $b_{b}(50)$ during dormancy loss was a linear function of storage temperature above a base temperature (Bauer et al., 1998). Thermal afterripening time is analogous to other thermal time models, as described by:

$$
\text { AT }=\left(\begin{array}{ll}
T_{\mathrm{S}} & T_{\mathrm{L}}
\end{array}\right) t_{\mathrm{ar}},
$$

where $\theta_{\mathrm{AT}}$ is the thermal time requirement for afterripening, $T_{\mathrm{S}}$ is the temperature of storage (or of the dry field seed bed), $T_{\mathrm{L}}$ is the base temperature for after-ripening, and $t_{\mathrm{ar}}$ is the after-ripening time required, i.e. the time required for ${ }_{b}(50)$ to decrease from its initial value to its final value (at a given incubation temperature). As the notation suggests, the time required for after-ripening decreases proportionately as the storage temperature increases above the base temperature. Bauer et al. (1998) successfully validated a thermal after-ripening time model for $B$. tectorum in the field under widely fluctuating summer temperatures, which suggests that the effect of fluctuating seed zone temperature is equivalent to a summation of the effects of short constant temperature intervals. However, a limitation of this thermal after-ripening time model was the fact that each incubation temperature required a unique set of parameters. A more general thermal afterripening model would require a single base temperature for after-ripening as well as an identical rate of change in ${ }_{b}(50)$ across incubation temperatures. The difference between initial and final

${ }_{b}(50)$ would then be the only variable affecting the value of $\theta_{\mathrm{AT}}$ at any incubation temperature.

Seeds may experience temporary hydration at values too low to permit radicle emergence in the field, and it is important to understand the effects of these events on hydrothermal time accumulation. Most research on such treatments has been in the area of seed priming, which has practical application particularly in the field of horticulture (e.g. Taylor et al., 1998). Incorporation of priming treatments into population-based models led to the concept of hydropriming time (Tarquis and Bradford, 1992) and hydrothermal priming time (Bradford and Haigh, 1994; Dahal and Bradford, 1994), which is similar in form to the general hydrothermal time equation:

$$
\text { HTP }=\left(\begin{array}{ll}
\text { prim } & \min
\end{array}\right)\left(\begin{array}{ll}
T_{\text {prim }} & T_{\min }
\end{array}\right) t_{p^{\prime}}
$$

where $\theta_{\text {HTP }}$ is the hydrothermal priming time constant, prim and $T_{\text {prim }}$ refer to the water potential and temperature conditions present during the 
priming event, ${ }_{\min }$ and $T_{\min }$ are the minimum water potential and temperature below which a seed does not progress toward germination during a priming treatment, and $t_{\mathrm{p}}$ is the duration of the priming event. As proposed by Bradford and colleagues (Dahal and Bradford, 1994; Cheng and Bradford, 1999), $\theta_{\mathrm{HTP}}$ is an indicator of the relationship between priming time and differences between ( prim $\left.^{-}{ }_{\text {min }}\right)$ and $\left(T_{\text {prim }}-T_{\text {min }}\right)$. $\theta_{\mathrm{HTP}}$ is usually much larger in magnitude than $\theta_{\mathrm{HT}}$ for a particular seed lot. The reason for this is that if min is considered to be constant across priming $\mathrm{s}$, the accrual of germination progress under priming conditions proceeds much more slowly at a given $\left(\right.$ prim $\left.^{-}{ }_{\text {min }}\right)$ than progress at higher, germinationpermissive $\mathrm{s}$ for a similar $\left(-{ }_{b}(50)\right)$.

To quantify the progress of seeds toward germination during priming, the amount of hydrothermal time (HTT) accumulation during exposure to a priming water potential can be determined using the following equation:

$$
=\mathrm{acc}^{+} \mathrm{req}^{\prime}
$$

where $\theta_{\text {HTacc }}$ represents the hydrothermal time accumulated during the priming event and $\theta_{\text {HTreg }}$ represents the remaining amount of hydrothermal time required for radicle emergence to occur. As with $\theta_{\mathrm{HT}}, \theta_{\mathrm{HTacc}}$ and $\theta_{\mathrm{HTreq}}$ are in units of MPa-degree-days. $\theta_{\text {HTreq }}$ can first be determined by substituting $\theta_{\text {HTreq }}$ for $\theta_{\mathrm{HT}}$ equation (1), using the ${ }_{\mathrm{b}}(50)$ value from the hydrothermal time equation for ${ }_{b}(g)$, and the time required in water ( $=0 \mathrm{MPa}$ ) following priming for $50 \%$ germination $\left(t_{50}\right)$ to occur as $t_{g}$. $\theta_{\mathrm{HTreq}}$ can then be subtracted from the known parameter $\theta_{\mathrm{HT}^{\prime}}$, resulting in $\theta_{\text {HTacc }}$

The value of $\theta_{\mathrm{HTP}}$ can then be determined by regressing accumulated HTT for the $50 \%$ fraction (i.e. analogous to the mean post-priming germination rate as used by Bradford and co-workers) on accumulated hydrothermal priming time calculated from equation (3), varying the value of min until the best fit is obtained and the $y$-intercept has a value of zero. This approach considers hydrothermal priming time (HTPT) and HTT to be directly proportional. The slope of the resulting regression line represents an estimate of the quantitative relationship between $\theta_{\mathrm{HT}}$ and $\theta_{\text {HTP }}$ :

$$
{ }_{\mathrm{HTP}}={ }_{\mathrm{HT}} /(\mathrm{HTT} / \mathrm{HTPT}) \text {. }
$$

This makes it possible to calculate expected HTT accumulation under any set of priming $T$ and conditions.

The present study was conducted pursuant to four objectives related to our long-term goal of developing a complete dormancy loss and germination model for Elymus elymoides (Raf.) Swezey (bottlebrush squirreltail; syn. Sitanion hystix (Nutt.) J. G. Smith), a perennial cool-season bunchgrass native to Intermountain Western North America. Our first objective in this research was to develop a hydrothermal time model for germination of $E$. elymoides. The second objective was to describe patterns of germination response to incubation temperature in terms of the hydrothermal time parameter $\left({ }_{b}(50)\right)$. The third objective was to develop a thermal time (degree-day) model for dormancy loss during dry after-ripening, using (50) as an index of dormancy status. The fourth objective was to determine the effects of incubation across a range of priming water potentials on HTT accumulation and to understand the relationship between priming and $T$ conditions and hydrothermal priming time parameters.

We hope to use the resulting model, as well as similar models for additional species, as a basis for predicting the phenology of dormancy loss and germination under the fluctuating conditions experienced by seeds in nature. This in turn will enable us to increase the success of restoration seedings in semi-arid ecosystems by placing seeding technology on a more sound scientific basis.

\section{Materials and methods}

Mature E. elymoides florets (hereafter seeds) were hand-collected in the summer of 1993. Seeds of this species exhibit varying degrees of conditional dormancy at maturity and lose dormancy through dry after-ripening (Beckstead et al., 1995). Seeds from two contrasting populations were used: Whiterocks, UT (elevation $1450 \mathrm{~m}$, mean January temperature $-3.6^{\circ} \mathrm{C}$, mean annual precipitation $176 \mathrm{~mm}$ ) and Santaquin, UT (elevation $1580 \mathrm{~m}$, mean January temperature $-3.3^{\circ} \mathrm{C}$, mean annual precipitation $415 \mathrm{~mm}$ ). Seeds were air-dried to a water content of $7-8 \%$ (dry weight basis), cleaned by rubbing and fanning, and hand-examined to ensure fill. Within 2 weeks following collection, seeds were stored in sealed plastic jars at 10,20 , or $30^{\circ} \mathrm{C}$ in the dark to dry after-ripen. Subsamples of seeds were removed as required. For each treatment, four replications of 25 seeds each were used.

\section{Temperature response and after-ripening experiment}

Recently harvested seeds were stored at 10,20 or $30^{\circ} \mathrm{C}$ for $0,4,8,12$ or 16 weeks. Following storage, subsamples of seeds were removed and germinated on water-saturated blue germination blotters (Anchor Paper, St. Paul, MN) in plastic $10 \mathrm{~cm}$ Petri dishes under each of the following temperature regimes: alternating regimes $(12 \mathrm{~h} / 12 \mathrm{~h})$ of $5 / 15,10 / 20,15 / 25$, or $20 / 30^{\circ} \mathrm{C}$ with fluorescent lighting corresponding to 
the warmer temperature, or in darkness at 10, 20 or $30^{\circ} \mathrm{C}$. Within an incubator, dishes were arranged randomly and stacked in clear plastic bags sealed with rubber bands to retard evaporation. Periodic addition of water ensured continual saturation of blotters. In treatments that included light, the top Petri dish in each stack contained blotters but no seeds to ensure that dishes containing seeds received similar light. Germination was recorded on days 1, 2, $4,7,11,14,21$, and $28 \mathrm{~d}$ of incubation. Viable, ungerminated seeds remaining after 28 days were classified as dormant; viability was determined using a cut test (Anonymous, 1998). Germination fractions were corrected for viability by dividing the number of germinated seeds by the number of viable seeds in each replicate.

\section{Hydrothermal time and seed priming experiment}

Fully after-ripened seeds (stored for $1 \mathrm{yr}$ in the laboratory and no longer dormant) were incubated in darkness at one of eight water potentials $(0,-0.5,-1$, $-1.5,-2,-4,-10$ or $-20.0 \mathrm{MPa})$ for $7 \mathrm{~d}$ at either 20 or $30^{\circ} \mathrm{C}$. For water potentials above $-4 \mathrm{MPa}$, seeds were placed on the surface of semi-permeable osmotic membranes (SpectraPor3) in contact with water or polyethylene glycol (PEG) solutions as described by Hardegree and Emmerich (1990). For values of -4 $\mathrm{MPa}$ and below, seeds were placed above saturated salt solutions in sealed jars as described by Allen et al. (1992). Germination (radicle emergence $\geqslant 1 \mathrm{~mm}$ ) was scored at $12 \mathrm{~h}$ intervals. After 1 week, ungerminated seeds were placed inside $10 \mathrm{~cm}$ Petri dishes on watersaturated blotters. These Petri dishes were then placed in dark incubators at the temperature of priming. Germination and viability were scored as above.

\section{Model development}

Values for hydrothermal time parameters were obtained as follows: $T_{\mathrm{b}}$ was assumed to be $0^{\circ} \mathrm{C}$ and constant, based on several experiments which showed that E. elymoides seeds at various dormancy levels germinate at $1^{\circ} \mathrm{C}$ (Meyer, unpublished data). Germination time course data for the 1 week priming treatment were analysed by repeated probit regression to estimate values for the hydrothermal time constant, $\theta_{\mathrm{HT}^{\prime}}$ the mean base water potential, ${ }_{b}(50)$, and the standard deviation of mean base water potentials, for each seed population. This approach is described in detail by Bauer et al. (1998) and Christensen et al. (1996), based on earlier work of Bradford (1990, 1995), Ellis et al. (1986), and Gummerson (1986).

b (50) values were also calculated for seeds at various stages of after-ripening, as described by Bauer et al. (1998). Briefly, equation (1) was used to solve for

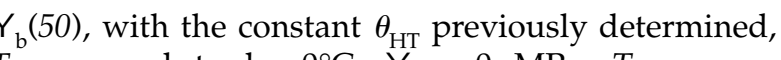
$T_{\mathrm{b}}$ assumed to be $0^{\circ} \mathrm{C},=0 \mathrm{MPa}, T=$ mean incubation temperature, and $t_{g}$ the actual days to $50 \%$ germination as interpolated from germination time courses. For time courses where final germination was less than $50 \%$, was used to calculate ${ }_{b}(50)$ from ${ }_{b}(g)$ of a fraction ${ }^{b}(g)$ that did germinate. Thus, a $b(50)$ value was obtained from the germination time course curve for each storage temperature by storage duration by incubation temperature combination.

The analysis of covariance (ANCOVA) procedure of SAS (SAS Institute, 1990) was used to evaluate the relationship between mean base water potential and mean incubation temperature. Incubation temperature was considered to be the continuous variable, and after-ripening status (recently harvested vs fully after-ripened) and seed population (collection) were considered class variables.

A thermal time after-ripening model was developed based on equation (2) as previously described (Bauer et al., 1998). o (50) values calculated using germination time courses obtained at different stages of after-ripening and at different incubation temperatures were regressed against thermal time expressed as $\left(T_{\mathrm{S}}-T_{\mathrm{L}}\right) t_{\mathrm{ar}}$, varying the value of $T_{\mathrm{L}}$ until the best fit was obtained. Repeated ANCOVA was used to perform this analysis for each seed population, with incubation temperature as the class variable and thermal time as the continuous variable. The resulting slope yielded the common decrement in

(50) per unit thermal time, while four intercepts gave initial $b(50)$ values at each incubation temperature. Evaluation of the slope by incubation temperature interaction term indicated whether or not a single decrement and a single $T_{\mathrm{L}}$ could be considered common to all incubation temperatures.

To quantify progress of seeds toward germination during priming, the amount of hydrothermal time accumulation during a 1 week exposure to each of a series of water potentials was determined, as described following equation (4) herein.

The HTPT equation of Dahal and Bradford (1993), our equation (3), was used to determine the relationship between priming treatments and HTT accumulation. Accumulated HTT was regressed on HTPT for each population-incubation temperature combination, manipulating the value of ${ }_{\min }$ until the $y$-intercept had a value of zero. Because only one priming time was used in this study, both slope and fit were unaffected by the value of $\min _{\text {. The resulting }}$ linear equations were then used to predict the relationship between HTP time and HTT accumulation and, therefore, the expected HTT accumulation under any priming scenario. We tested the hypothesis that the slope of this relationship was equivalent across incubation temperatures and populations using ANCOVA with HTT as the dependent variable, HTPT 
as the continuous variable, and population and incubation temperature as class variables.

\section{Results}

\section{Hydrothermal time analysis}

Hydrothermal time models fit to data for E. elymoides had high $R^{2}$ values, indicating a high degree of congruency between predicted and observed germination time course curves (Table 1). Both E. elymoides seed populations used in this study had relatively slow germination rates, due largely to a lengthy HTT requirement. $\theta_{\mathrm{HT}}$ values were similar for both populations. ${ }_{b}(50)$ values for fully after-ripened seeds were highly negative, particularly at the lower $\left(20^{\circ} \mathrm{C}\right)$ incubation temperature. The standard deviation of base water potentials was approximately $50 \%$ greater for the Whiterocks collection than the Santaquin collection, which indicated a greater spread in time to germination.

\section{Incubation temperature relations}

(50) increased linearly with incubation temperature for both recently harvested and fully after-ripened seeds (Fig. 1). The slopes of the relationship between b (50) and incubation temperature were identical regardless of seed population or after-ripening status; only the intercepts were significantly different (Table $2)$. Because ${ }_{b}(50)$ in recently harvested seeds was greater than $0 \mathrm{MPa}$ above approximately $25^{\circ} \mathrm{C}$, more than half the seeds from each population were not capable of germinating above this temperature even in free water. Virtually all fully after-ripened seeds were capable of germinating in water even at $30^{\circ} \mathrm{C}$, but because accumulation of hydrothermal time occurred more slowly at high incubation temperatures, germination rate did not increase as incubation temperature increased. The increased accumulation of hydrothermal time associated with the increased temperature difference $\left(T-T_{\mathrm{b}}\right)$ was offset by the decreased accumulation of hydrothermal time associated with a small $\left(-{ }_{b}(g)\right)$ difference due to the high base water potential. This relationship explains the apparent broad range of optimum incubation temperatures for fully after-ripened $E$. elymoides seeds (Beckstead et al., 1995). A further consequence of the parallel slopes in Fig. 1 was that the size of change in ${ }_{b}(50)$ during dormancy loss was uniform across incubation temperatures.

Calculated ${ }_{b}(50)$ values at a given mean temperature were consistently higher in the dark at constant temperature than in the light with alternating temperature, indicating some germination stimulation by light or temperature alternation (Fig. 1). This effect was minor in relation to the ${ }_{b}(50)$ change during

Table 1. Hydrothermal time parameters for two Elymus elymoides seed collections derived from experiments with fully after-ripened seeds incubated at two constant temperatures $\left(20\right.$ and $\left.30^{\circ} \mathrm{C}\right)$ and five water potentials $(0$ to $-2.0 \mathrm{MPa})$.

\begin{tabular}{|c|c|c|}
\hline Parameter & Whiterocks collection & Santaquin collection \\
\hline$\theta_{\mathrm{HT}}$ (MPa-degree-days) & 108.3 & 104.2 \\
\hline$(50)$ at $20^{\circ} \mathrm{C}(\mathrm{MPa})$ & -1.41 & -1.29 \\
\hline$(50)$ at $30^{\circ} \mathrm{C}(\mathrm{MPa})$ & -0.88 & -0.71 \\
\hline$(\mathrm{MPa})$ & 0.423 & 0.277 \\
\hline$R^{2^{\mathrm{b}}}$ & 0.926 & 0.952 \\
\hline$n$ & 29 & 29 \\
\hline
\end{tabular}

Table 2. ANCOVA results for the relationships between the dependent variable mean base water potential and incubation temperature (continuous variable), after-ripening status (recently harvested vs fully after-ripened, class variable) and Elymus elymoides seed population (class variable). The $R^{2}$ value was 0.973 , and the common slope of change in $b_{b}(50)$ as a function of incubation temperature was $0.056 \mathrm{MPa} /$ degree.

\begin{tabular}{lccc}
\hline Effect & DOF & $F$ value & $\begin{array}{c}\text { Probability } \\
\text { level }\end{array}$ \\
\hline Incubation temperature (ITEMP) & 1 & 144.3 & 0.0001 \\
After-ripening status (ARSTATUS) & 1 & 491.8 & 0.0001 \\
Seed population (SEEDPOP) & 1 & 0.7 & n.s. \\
ITEMP $\times$ ARSTATUS & 1 & 0.1 & n.s. \\
ITEMP $\times$ SEEDPOP & 1 & 0 & n.s. \\
ARSTATUS $\times$ SEEDPOP & 1 & 10.1 & 0.0051 \\
ITEMP $\times$ ARSTATUS $\times$ SEEDPOP & 1 & 0.5 & n.s. \\
\hline
\end{tabular}




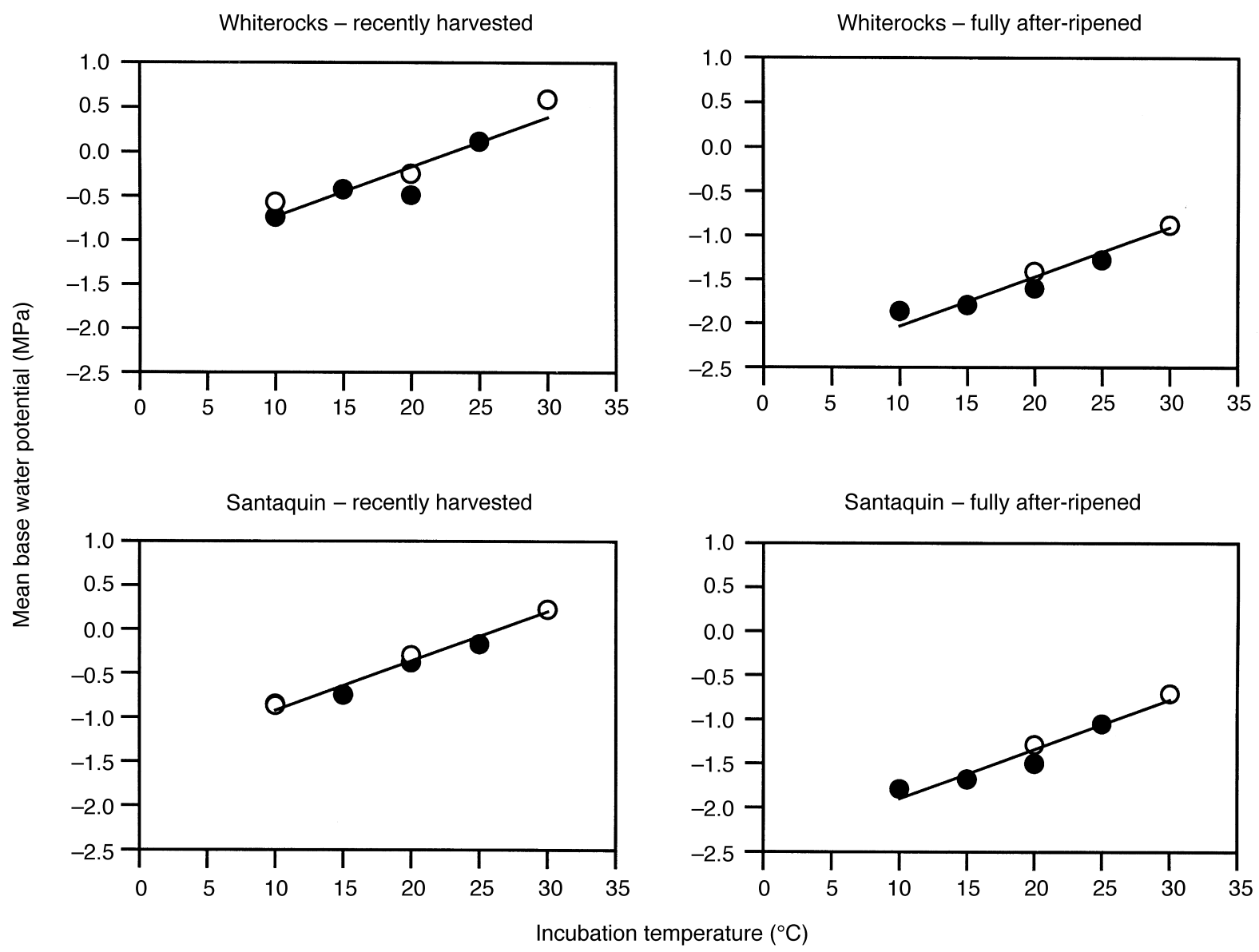

Figure 1. The relationship between mean base water potential and incubation temperature for recently harvested and fully after-ripened seeds from two Elymus elymoides populations. Closed circles represent alternating regimes in the light; open circles represent constant regimes in the dark. The plotted regression lines have a common slope derived from analysis of covariance (ANCOVA) but have significantly different $y$-intercepts (see Table 2 for details).

dormancy loss and was of similar magnitude for both recently harvested and fully after-ripened seeds.

\section{Thermal time model for dormancy loss during dry after-ripening}

Thermal time models adequately described temperature dependence of the rate of dormancy loss for both seed populations (Fig. 2, Table 3). Afterripening rates were normalized across storage temperatures by using a thermal time model, so that changes in ${ }_{b}(50)$ values could be expressed on a thermal time basis. Because the interaction between thermal time and incubation temperature was not significant, the relationship between ${ }_{b}(50)$ and thermal time could further be characterized as having a single common slope and a single after-ripening base temperature across all incubation temperatures for each seed population (Table 3). This common slope represents the decrement in ${ }_{b}(50)$ per degree- day. Because of the uniform difference between initial and final ${ }_{b}(50)$ values across incubation temperatures, the thermal time requirement for after-ripening, i.e. $\theta_{\mathrm{AT}}$, was also a constant. Both the base temperature and slope were slightly greater for Whiterocks than Santaquin, resulting in similar rates of dormancy loss in real time.

\section{Hydrothermal time accumulation during priming}

Fully after-ripened seeds accumulated hydrothermal time at water potentials as low as $-20 \mathrm{MPa}$ during a 1 week priming treatment (Fig. 3). Progress toward germination at reduced water potentials led to a decreased incubation requirement for germination following transfer to water. Hydrothermal time accumulation decreased linearly with decreasing in the higher range of water potentials $(-0.5$ to $-4 \mathrm{MPa}$ ) but generally levelled off at lower priming water potentials $(-4$ to $-20 \mathrm{MPa})$. Seeds were able to 

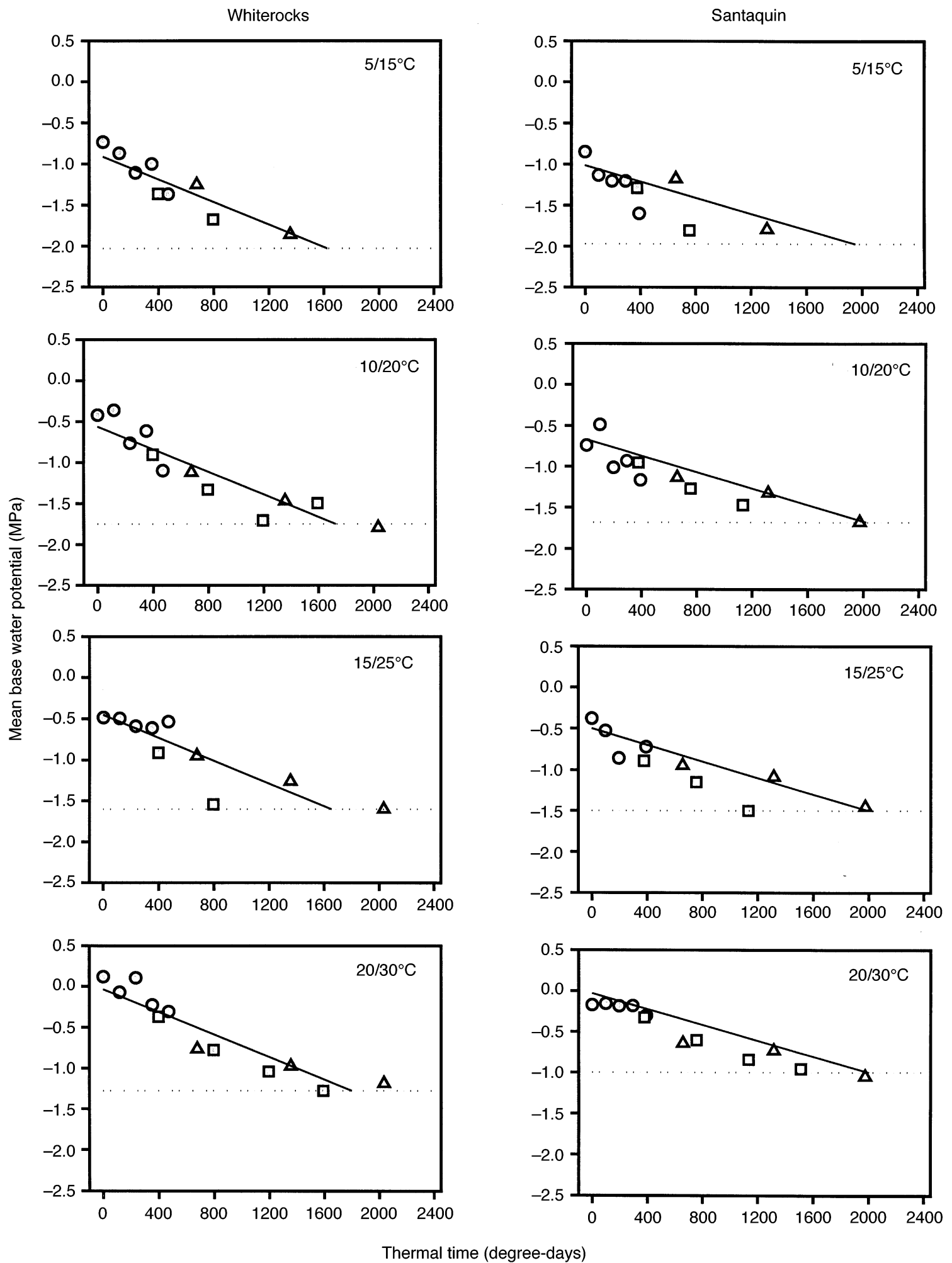

Figure 2. Fit of thermal after-ripening time models to data from storage experiments with seeds from two Elymus elymoides populations. Storage temperatures: $10^{\circ} \mathrm{C}$ (circles); $20^{\circ} \mathrm{C}$ (squares); $30^{\circ} \mathrm{C}$ (triangles). Plotted lines are from ANCOVA (see Table 3 for details). Horizontal dotted lines represent ${ }_{b}(50)$ values for fully after-ripened seeds. The value on the $x$-axis at the junction of the regression line with the horizontal line represents $\theta_{\mathrm{HT}}$. 
Table 3. Results of thermal after-ripening time ANCOVAs by seed population for seeds from two populations of Elymus elymoides. Mean base water potential, an index of dormancy status, is the dependent variable.

\begin{tabular}{lcc}
\hline & Whiterocks & Santaquin \\
\hline Thermal time (degree-days) & $F=142$ & $F=110$ \\
& $\mathrm{df}=1 ; P<0.0001$ & $\mathrm{df}=1 ; P<0.0001$ \\
Incubation temperature & $F=35.0$ & $F=78$ \\
& $\mathrm{df}=3 ; P<0.0001$ & $\mathrm{df}=3 ; P<0.0001$ \\
Thermal time by incubation & $F=0.6$ & $F=0.8$ \\
$\quad$ temperature interaction & $\mathrm{df}=3 ; P=0.65$ (n.s.) & $\mathrm{df}=3 ; P=0.52$ (n.s.) \\
$T_{\mathrm{L}}$ (base after-ripening temperature) & $5.8^{\circ} \mathrm{C}$ & $2.5^{\circ} \mathrm{C}$ \\
Common $\theta_{\text {AT }}$ (degree-days) & 1680 & 1970 \\
Common slope (MPa/degree-day) & -0.00069 & -0.00050 \\
$R^{2}$ & 0.877 & 0.908 \\
\hline
\end{tabular}
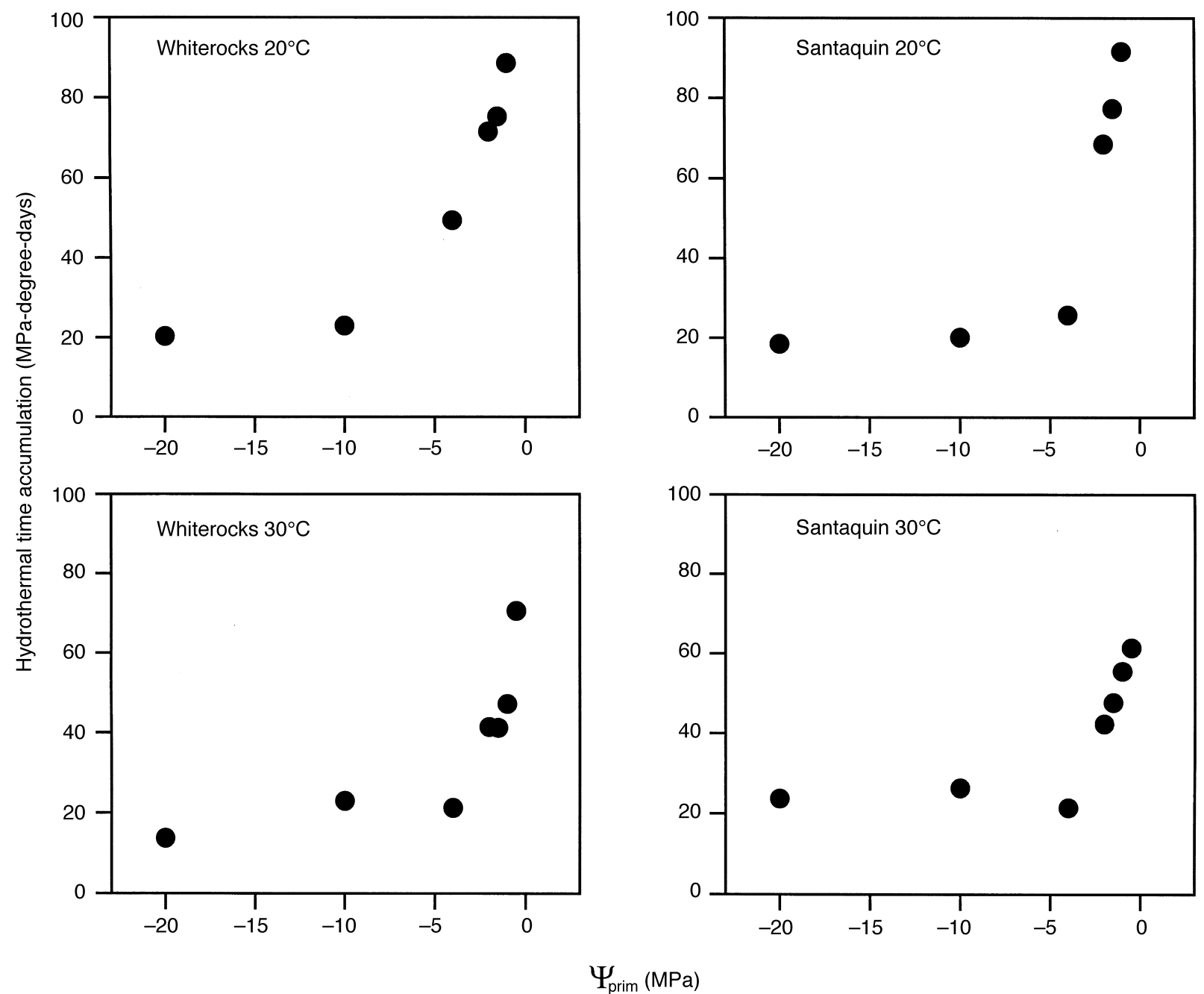

Figure 3. Hydrothermal time accumulation during a week of priming plotted as a function of priming water potential for fully after-ripened seeds from two populations of Elymus elymoides primed and incubated at two temperatures. 
accumulate about $20 \%$ of $\theta_{\mathrm{HT}}$ during exposure to the lower range. Seed response to priming at low was similar for the two seed populations.

A constant min hydrothermal priming time model provided a good fit overall $\left(R^{2}=0.968\right)$ of accumulated HTT to HTP time (Table 4, Fig. 4). The slopes for the $30^{\circ} \mathrm{C}$ priming treatment were significantly less than those for the $20^{\circ} \mathrm{C}$ treatment, indicating significantly larger $\theta_{\mathrm{HTP}}$ values at the higher temperature. For the Whiterocks population, ${ }_{\min }$ was also higher at the higher incubation temperature $(-5.5$ vs $-8.0 \mathrm{MPa})$, whereas for the Santaquin population the two values were similar ( -5.8 vs $-5.3 \mathrm{MPa}$, respectively). The Santaquin population had significantly steeper slopes and therefore smaller $\theta_{\mathrm{HTP}}$ values overall than the Whiterocks population.

\section{Discussion}

Gummerson (1986) suggested that the hydrothermal time parameters $\theta_{\mathrm{HT}^{\prime}}{ }_{\mathrm{b}}(50), T_{\mathrm{b}^{\prime}}$ and ${ }_{\mathrm{b}}$ could

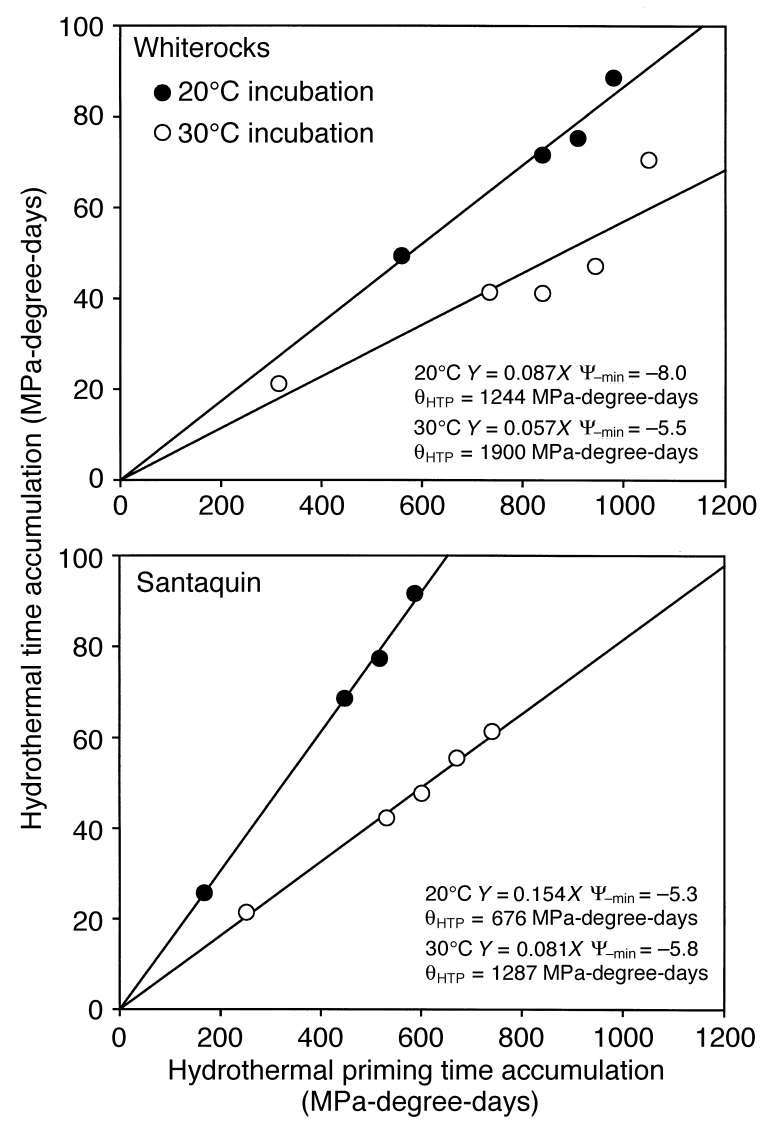

Figure 4. Priming data fit to a constant psi-minimum hydrothermal priming time model. Accumulated hydrothermal time is plotted as a function of hydrothermal priming time for fully after-ripened seeds from two Elymus elymoides populations primed and incubated at two temperatures. See Table 4 for details. "provide a concise and meaningful way of comparing samples of seeds". Unfortunately, there are few published reports of hydrothermal time analysis, especially for non-crop species. In a recent paper presenting hydrothermal time analysis for a wide range of wild species, we reported that E. elymoides had hydrothermal time parameter values well within the range for other bodenvag (soil generalist) species (Allen et al., 2000). It had higher $\theta_{\mathrm{HT}}$ values than most other bodenvag species, resulting in slow germination rates in spite of relatively low ${ }_{b}(50)$ values. Its values were also relatively small. The $T_{\mathrm{b}}$ value of $0^{\circ} \mathrm{C}$ was characteristic of many species of Intermountain North America, where germination under snow cover in winter is a principal mode of seedling establishment (Meyer et al., 1989; Meyer and Monsen, 1991; Meyer et al., 1995).

Elymus elymoides seeds in this study had two important characteristics not observed in related studies with B. tectorum. First, $\quad$ (50) increased linearly with incubation temperature in both recently harvested and fully after-ripened seeds. Therefore, an increased incubation temperature did not lead to an increased germination rate, resulting in relatively slow rates (3-4 $\mathrm{d}$ to $50 \%$ ) across a broad range of temperatures (Beckstead et al., 1995). In contrast, ${ }_{b}(50)$ for B. tectorum increased with temperature of incubation only above a well-defined optimum; below this temperature values of $b_{b}(50)$ were constant, and germination rate increased with temperature. In recently harvested seeds of $B$. tectorum, the optimum incubation temperature was $<15^{\circ} \mathrm{C}$, while in fully after-ripened seeds its value increased to $>25^{\circ} \mathrm{C}$ (Christensen et al., 1996). Second, the decrement in ${ }_{b}(50)$ per degree-day during dormancy loss was constant across incubation temperatures for E. elymoides seeds. This was not the case with $B$. tectorum seeds, which required a unique set of thermal after-ripening time parameters at each incubation temperature (Bauer et al., 1998). In particular, higher incubation temperatures were associated in B. tectorum with higher $T_{\mathrm{L}}$ and $\theta_{\mathrm{AT}}$ values.

The decrease in ${ }_{b}(g)$ values that accompanies loss of dormancy is consistent with previous studies suggesting that the water potential threshold is closely tied to dormancy and germination status. For example, an increase in ${ }_{b}(g)$ was associated with induction of thermodormancy in lettuce seeds imbibed at high incubation temperatures (Dutta and Bradford, 1994). Similarly, gibberellic acid (GA) deficiency in tomato seeds correlated with high ${ }_{b}(g)$ values which decreased following GA applications that broke dormancy and increased following abscisic acid applications that prevented radicle emergence (Ni and Bradford, 1993a, b).

Elymus elymoides seeds accumulated a limited and uniform amount of hydrothermal time during priming treatments at values from -4 to $-20 \mathrm{MPa}$. 
Table 4. Results of ANCOVA for the hydrothermal priming time model. The dependent variable is accumulated hydrothermal time, the continuous variable is hydrothermal priming time, and the class variables are temperature and seed population.

\begin{tabular}{lccc}
\hline Effect & F value & df & $P$ \\
\hline Hydrothermal priming time main effect & 189.1 & 1 & $<0.0001$ \\
Temperature main effect & - & - & n.s. \\
Seed population main effect & - & - & n.s. \\
HTPT $\times$ temperature & 14.0 & 1 & 0.0039 \\
HTPT $\times$ seed population & 11.1 & 1 & 0.0077 \\
Temperature $\times$ seed population & - & - & n.s. \\
HTPT $\times$ temperature $\times$ seed population & - & - & n.s. \\
\hline
\end{tabular}

Certain physiological processes related to germination can occur at water potentials in this range (Vertucci, 1989; Vertucci and Farrant, 1995). The advancement effect we observed at these low values may have at least partially been due to positive effects associated with humidification of seeds (Vertucci and Leopold, 1984). If so, it would not have been preserved through drying treatments traditionally associated with priming. Over the range from 0 to $-4 \mathrm{MPa}$, hydrothermal time accumulation decreased linearly with . A hydrothermal priming time model using a constant min gave a generally adequate fit to our data over this range. The priming effect we observed over the range 0 to $-4 \mathrm{MPa}$ probably represents true priming, i.e germination advancement that would be preserved through drying. The constant min determined for each population and incubation temperature represents the min below which true priming would not take place.

It is not yet clear whether laboratory priming experiments have much relevance under field conditions. Data from laboratory studies involving partially hydrated seeds can be difficult to interpret owing to seed deterioration following prolonged exposure to intermediate $\mathrm{s}$ as well as the fact that such studies generally include constant environmental conditions that seeds would almost never encounter in the field. In contrast with priming treatments that aim to enhance seed performance through exposure to controlled and $T$ conditions prior to planting (e.g. Taylor et al., 1998), E. elymoides seeds in the field experience continuous, simultaneous fluctuations of and temperature, including periodic dehydration to levels below the priming range. While we have largely verified that advancement toward germination through intermittent exposure to free water via hydrationdehydration cycles can be characterized by summation of hydration periods (Allen et al., 1993a, b), rapid drying imposed shortly before radicle emergence can alter germination rates upon return to water (Debaene-Gill et al., 1994; Taylor et al., 1998). A recently proposed model of seed germination that allows variation in osmotic potential (i.e. a virtual osmotic potential) may also have promise in dealing with the effects of variable during incubation (Rowse et al., 1999).

The simple relationships between hydrothermal time parameters and temperature response, dormancy loss, and priming observed in E. elymoides strongly suggest that hydrothermal time theory has an underlying physiological basis and is not just another way of empirically fitting germination time course data. We are hopeful that this conceptual framework will continue to facilitate efforts to understand and to model dormancy loss and germination phenology, for E. elymoides and other species, in the complex, fluctuating environment of the field seed zone.

\section{Acknowledgements}

This project was funded in part by Grant No. CSRS93-3932 from the USDA Cooperative State Research Service. We gratefully acknowledge the technical assistance of Julie Beckstead, Maren Christensen Bauer, and Hidi Pullman.

\section{References}

Allen, P.S. and Meyer, S.E. (1998) Ecological aspects of seed dormancy loss. Seed Science Research 8, 183-191.

Allen, P.S., White, D.B., Russer, K. and Olson, G. (1992) A method for controlling water potential in seed germination research. HortScience 27, 364-366.

Allen, P.S., Debaene, S.B.G. and Meyer, S.E. (1993a) Regulation of grass seed germination under fluctuating moisture regimes. pp. 387-392 in Côme, D., Corbineau, F. (Eds) Proceedings of the fourth international workshop on seeds. Paris, ASFIS.

Allen, P.S., White, D.B. and Markhart, A.H. (1993b) Germination of perennial ryegrass and annual bluegrass seeds subjected to hydration-dehydration cycles. Crop Science 33, 1020-1025.

Allen, P.S., Meyer, S.E. and Khan, M.A. (2000) Hydrothermal time as a tool in comparative germination studies. pp. 401-410 in Black, M.; Bradford, K.J.; 
Vazquez-Ramos, J. (Eds) Seed biology: advances and applications, Wallingford, CAB International.

Anonymous (1998) Rules for testing seeds. Lincoln, NE, Association of Official Seed Analysts.

Bauer, M.C., Meyer, S.E. and Allen, P.S. (1998) A simulation model to predict seed dormancy loss in the field for Bromus tectorum L. Journal of Experimental Botany 49, 1235-1244.

Beckstead, J., Meyer, S.E. and Allen, P.S. (1995) Effects of after-ripening on cheatgrass (Bromus tectorum) and squirreltail (Elymus elymoides) germination. pp. 165-172 in Roundy, B.A.; McArthur, E.D.; Haley, J.S.; Mann, D.K. (Compilers) Proceedings: Wildland shrub and arid land restoration symposium. USDA Forest Service General Technical Report INT-GTR-315, Ogden, UT, USDA.

Bradford, K.J. (1990) A water relations analysis of seed germination rates. Plant Physiology 94, 840-849.

Bradford, K.J. (1995) Water relations in seed germination. pp. 351-396 in Kigel, J.; Galili, G. (Eds) Seed development and germination. New York, Marcel Dekker.

Bradford, K.J. and Haigh, A.M. (1994) Relationship between accumulated hydrothermal time during seed priming and subsequent seed germination rates. Seed Science Research 4, 63-69.

Cheng, Z.Y. and Bradford, K.J. (1999) Hydrothermal time analysis of tomato seed germination responses to priming treatments. Journal of Experimental Botany 50, 89-99.

Christensen, M., Meyer, S.E. and Allen, P.S. (1996) A hydrothermal time model of seed after-ripening in Bromus tectorum L. Seed Science Research 6, 155-163.

Dahal, P. and Bradford, K.J. (1994) Hydrothermal time analysis of tomato seed germination at suboptimal temperature and reduced water potential. Seed Science Research 4, 71-80.

Dahal, P., Bradford, K.J. and Haigh, A.M. (1993) The concept of hydrothermal time in seed germination and priming. pp. 1009-1014 in Côme, D.; Corbineau, F. (Eds) Proceedings of the fourth international workshop on seeds: basic and applied aspects of seed biology. Paris, ASFIS.

Debaene-Gill, S.B., Allen, P.S. and White, D.B. (1994) Dehydration of germinating perennial ryegrass seeds can alter rate of subsequent radicle emergence. Journal of Experimental Botany 45, 1301-1307.

Dutta, S. and Bradford, K.J. (1994) Water relations of lettuce seed thermoinhibition. II. Ethylene and endosperm effects on base water potential. Seed Science Research 4, 11-18.

Ellis, R.H., Covell, S., Roberts, E.H. and Summerfield, R.J. (1986) The influence of temperature on seed germination rate in grain legumes. II. Intraspecific variation in chickpea at constant temperatures. Journal of Experimental Botany 37, 1503-1515.

Gummerson, R.J. (1986) The effect of constant temperatures and osmotic potentials on the germination of sugar beet. Journal of Experimental Botany 37, 729-741.

Hardegree, S.P. and Emmerich, W.E. (1990) Partitioning water potential and specific salt effects on seed germination of four grasses. Annals of Botany 66, 587-595.

Meyer, S.E. and Monsen, S.B. (1991) Habitat-correlated variation in mountain big sagebrush (Artemisia tridentata ssp. vaseyana) seed germination patterns. Ecology 72, 739-742.

Meyer, S.E., McArthur, E.D. and Jorgensen, G.R. (1989) Variation in germination response to temperature in rubber rabbitbrush (Chrysothamnus nauseosus: Asteraceae) and its ecological implications. American Journal of Botany 76, 981-991.

Meyer, S.E., Kitchen, S.G. and Carlson, S.L. (1995) Seed germination timing patterns in Intermountain Penstemon. American Journal of Botany 82, 377-389.

Ni, B.R. and Bradford, K.J. (1992) Quantitative models characterizing seed germination responses to abscisic acid and osmoticum. Plant Physiology 98, 1057-1068.

Ni, B.R. and Bradford, K.J. (1993a) Germination and dormancy of abscisic acid- and gibberellin-deficient mutant tomato (Lycopersicon esculentum) seeds. Sensitivity of germination to abscisic acid, gibberellin and water potential. Plant Physiology 101, 607-617.

Ni, B.R. and Bradford, K.J. (1993b) Sensitivity of ABA- and GA-deficient mutant tomato seeds to ABA, GA and water potential. pp. 555-560 in Côme, D.; Corbineau, F. (Eds) Proceedings of the fourth international workshop on seeds: basic and applied aspects of seed biology. Paris, ASFIS.

Rowse, H.R., McKee, J.M.T. and Higgs, E.C. (1999) A model of the effects of water stress on seed advancement and germination. New Phytologist 143, 273-279.

Saleki, R., Young, P.G. and Lefebvre, D.D. (1993) Mutants of Arabidopsis thaliana capable of germination under saline conditions. Plant Physiology 101, 839-845.

SAS Institute (1990) SAS procedures guide version six (3rd edition). Cary, NC, SAS Institute Inc.

Tarquis, A.M. and Bradford, K.J. (1992) Prehydration and priming treatments that advance germination also increase the rate of deterioration of lettuce seeds. Journal of Experimental Botany 43, 307-317.

Taylor, A.G., Allen, P.S., Bennett, M.A., Bradford, K.J., Burris, J.S. and Misra, M.K. (1998) Seed enhancements. Seed Science Research 8, 245-256.

Vertucci, C.W. (1989) The effects of low water contents on physiological activities of seeds. Physiologia Plantarum 77, 172-176.

Vertucci, C.W . and Farrant, J.M. (1995) Acquisition and loss of desiccation tolerance. pp. 237-272 in Kigel, J.; Galili, G. (Eds) Seed development and germination. New York, Marcel Dekker.

Vertucci, C.W. and Leopold, A.C. (1984) Bound water in soybean seed and its relation to respiration and imbibitional leakage. Plant Physiology 75, 114-117.

Welbaum, G.E., Tissaoui, T. and Bradford, K.J. (1990) Water relations of seed development and germination in muskmelon (Cucumis melo L.). III. Sensitivity of germination to water potential and abscisic acid during development. Plant Physiology 92, 1029-1037.

Received 7 September 1999

accepted after revision 23 February 2000 (c) CAB International, 2000 